\title{
A Novel Arabidopsis-Colletotrichum Pathosystem for the Molecular Dissection of Plant-Fungal Interactions
}

\author{
Richard O'Connell,, ${ }^{1}$ Corentin Herbert, ${ }^{1}$ Surapareddy Sreenivasaprasad, ${ }^{2}$ Moustafa Khatib, ${ }^{1}$ \\ Marie-Thérèse Esquerré-Tugayé, ${ }^{1}$ and Bernard Dumas ${ }^{1}$ \\ 1UMR 5546, CNRS-Université Paul Sabatier, Pôle de Biotechnologie Végétale, 24 Chemin de Borde Rouge, BP17 Auzeville, \\ 31326 Castanet-Tolosan, France; ${ }^{2}$ Horticulture Research International-Wellesbourne, Warwickshire CV35 9EF, U.K.
}

Submitted 29 August 2003. Accepted 12 November 2003.

\begin{abstract}
The ability of a Colletotrichum sp., originally isolated from Brassica campestris, to infect Arabidopsis thaliana was examined. Sequence analysis of the internal transcribed spacer (ITS)1, 5.8S RNA gene and ITS2 regions of ribosomal (r)DNA showed the pathogen to be Colletotrichum destructivum. The host range was broad, including many cruciferous plants and some legumes. At $25^{\circ} \mathrm{C}$, all $A$. thaliana accessions tested were susceptible to the Brassica isolates of $C$. destructivum; however, at $15^{\circ} \mathrm{C}$, the accession Ws- 2 showed a temperature-dependant resistance, in which single epidermal cells underwent a rapid hypersensitive response. Legume isolates of $C$. destructivum were unable to infect $A$. thaliana and induced deposition of callose papillae at sites of attempted penetration. In compatible interactions, $C$. destructivum showed a two-stage, hemibiotrophic infection process. The initial biotrophic phase was associated with large, intracellular primary hyphae and was confined to one epidermal cell; whereas, in the subsequent necrotrophic phase, narrow secondary hyphae extensively colonized the tissue and conidia were produced in acervuli. An efficient transformation system was established for $C$. destructivum, using Agrobacterium-mediated transfer of DNA. The ability to genetically manipulate both partners in the interaction is an important advantage, and the Arabidopsis-Colletotrichum pathosystem should provide a valuable new model for dissecting plant-fungal interactions.
\end{abstract}

Additional keywords: Agrobacterium-mediated transformation, biotrophy, Colletotrichum higginsianum, GFP, rDNA-ITS.

Arabidopsis thaliana has become an important model host for studying plant-pathogen interactions due to the availability of a complete genomic sequence and an extensive collection of mutants, the ease of genetic and mutational analysis, and the possibility of using microarrays for gene expression analysis. A large number of fungal and oomycete pathogens have been reported to infect $A$. thaliana, either naturally or in the laboratory. These include obligate biotrophs (e.g., Peronospora, Albugo, and Erysiphe), hemibiotrophs (i.e. facultative biotrophs; e.g., Phytophthora), and necrotrophs (e.g., Alternaria, Botrytis, and Rhizoctonia) (Adam et al. 1999; Holub et al. 1995; Koch and Slusarenko 1990a,b; Roetschi et al. 2001; Thomma et al. 1999).

Corresponding author: Richard O'Connell

E-mail: oconnel@smcv.ups-tlse.fr

EMBL sequence accession numbers: AJ 558106, AJ 558107, AJ 558108, AJ 558109, AJ 558110, AJ 558111.
Interactions involving a downy mildew (Peronospora parasitica) and three powdery mildews (Erysiphe cichoracearum, E. cruciferarum, and $E$. orontii) have been used extensively to study recognition of pathogens by plants and the network of signaling pathways required for active plant defense (Botella et al. 1998; Parker et al. 2000; Reuber et al. 1998; Xiao et al. 2001). However, molecular analysis of the pathogens themselves has been limited because Peronospora and Erysiphe spp. are nonculturable, obligate biotrophs (i.e., they require a living host plant for their growth and reproduction and, therefore, are not amenable to genetic transformation). Although related pathogens, such as Phytophthora and Blumeria spp., have been transformed successfully (Chaure et al. 2000; Judelson 1996), this has not been reported for Erysiphe or Peronospora spp. The latter organism also is diploid, which complicates classical genetic analysis and gene knock-out experiments.

The large Ascomycete genus Colletotrichum is one of the most economically important groups of plant pathogens, causing anthracnose disease or blight on an extremely wide range of temperate and tropical crops, including grain and pasture legumes, cereals, and fruits (Bailey and Jeger 1992). As experimental systems, Colletotrichum spp. have the advantage of being haploid organisms, which can be cultured axenically, and transformed, which facilitates mutational analysis and the critical assessment of gene function by targeted disruption (Epstein et al. 1998; Redman et al 1999; Redman and Rodriguez 1994; Thon et al. 2000). Furthermore, many Colletotrichum spp. utilize an interesting hemibiotrophic infection strategy, in which the pathogen initially develops inside living host cells, before switching to a destructive necrotrophic mode of infection (O'Connell et al. 1985, 1993; Wharton et al. 2001). In addition, these fungi differentiate a series of specialized structures required for infection, including germ tubes, appressoria, infection pegs, biotrophic primary hyphae, and necrotrophic secondary hyphae (Perfect et al. 1999). For these reasons, species of Colletotrichum have provided attractive models for research on the molecular basis of fungal pathogenicity (Centis et al. 1997; Dufresne et al. 2000; Perfect et al. 2000; Takano et al. 1997; Yang and Dickman, 1999).

There have been no reports of any Colletotrichum spp. causing natural infections of $A$. thaliana. In the present study, we show that isolates of Colletotrichum destructivum O'Gara originating from Brassica campestris are able to infect Arabidopsis spp. in laboratory inoculation experiments. Importantly, we also demonstrate that the pathogen can be transformed with high efficiency by T-DNA transfer mediated by Agrobacterium tumefaciens. As a model pathosystem, the ArabidopsisColletotrichum interaction, therefore, has the significant advantage that both organisms can be manipulated genetically. 


\section{RESULTS}

\section{Characterization of the pathogen.}

Two isolates of $C$. higginsianum Sacc. (IMI 349061 and IMI 349063), originating from B. campestris subsp. chinensis (Pak-Choi), were obtained from CABI Bioscience (Egham, Surrey, U.K.). The colony morphology of IMI 349063 was highly variable, and examination of single-spore cultures derived from it showed that it comprised two distinct isolates, designated 349063A and 349063B. Isolate 349063A produced slow-growing, bright-orange colonies and sporulated poorly. In contrast, both $349063 \mathrm{~B}$ and 349061 produced dark, olivebrown to black colonies containing abundant melanized sclerotia, and both sporulated profusely. All the isolates had straight, cylindrical conidia with obtuse apices. Conidia of isolate IMI $349063 \mathrm{~A}$ were $15.25 \pm 2.18 \mu \mathrm{m}$ long (mean \pm standard deviation of 100 spores) and $4.67 \pm 0.39 \mu \mathrm{m}$ wide. However, those of isolates IMI 349063B (18.76 $\pm 0.85 \mu \mathrm{m}$ by $3.89 \pm$ $0.15 \mu \mathrm{m})$ and IMI $349061(18.77 \pm 1.15 \mu \mathrm{m}$ by $3.91 \pm 0.19$ $\mu \mathrm{m})$ were significantly $(P<0.001)$ longer and narrower. The dormant conidia of all isolates were unicellular but became septate upon germination (Fig. 1). At $25^{\circ} \mathrm{C}$, a single germ tube began to emerge from conidia by $2 \mathrm{~h}$, and the germ-tube apex began to swell by $3 \mathrm{~h}$. Appressoria were fully expanded by $5 \mathrm{~h}$, and melanization was complete at $8 \mathrm{~h}$. Mature appressoria of all three isolates generally were ovate (approximately 8 by 6 $\mu \mathrm{m}$ ) with an irregular, lobed margin (Fig. 1). On hydrophobic substrata such as polystyrene and plant tissue, the appressoria were either sessile or subtended by a very short germ tube.

Nucleotide sequences of the internal transcribed spacer (ITS) regions of ribosomal (r)DNA (ITS1 and ITS2) and the 5.8S RNA gene were determined for the three test isolates (IMI 349061, IMI 349063A, and IMI 349063B) and three reference isolates of $C$. destructivum (LARS 056, LARS 202, and LARS 319) (Table 1). In addition, the ITS sequences of four $C$. destructivum isolates and two $C$. higginsianum isolates were downloaded from EMBL and included in the comparative analysis. The three test isolates had identical sequences and were 98.7 to $100 \%$ identical to all other $C$. higginsianum and C. destructivum isolates (Fig. 2). The two reference $C$. higginsianum isolates (MAFF 305635 and $\mathrm{CH}-90$ ) were identical.
Three reference $C$. destructivum isolates from tobacco (ATCC 10921, ATCC 11995, and N150) and a fourth one from lentil (UQ343) showed 98.1 to $99.8 \%$ identity to each other. A phylogenetic analysis including other Colletotrichum spp. showed that the three test isolates formed a single group together with the reference isolates of $C$. destructivum and $C$. higginsianum that was supported by $99 \%$ bootstrap (Fig. 3). Previous studies have shown high levels of intraspecific variability in rDNA regions among some Colletotrichum spp. (Sherriff et al. 1994; Sreenivasaprasad et al. 1996). For example, the level of similarity within the ITS region ranged from 94.5 to $100 \%$ in $C$. acutatum and 96.5 to $100 \%$ in $C$. gloeosporioides. In this context, the high level of overall similarity observed (97.9 to $100 \%$ identity; Fig. 2) between the test isolates and the previously characterized $C$. destructivum and $C$. higginsianum isolates suggests that they all belong to a single species. For this reason, isolates IMI 349061, IMI 349063A, and IMI 349063B will be referred to hereafter as $C$. destructivum.

\section{Host range and infection \\ of Arabidopsis defense-pathway mutants.}

The host range of $C$. destructivum isolates IMI 349061, IMI 349063A, and IMI 349063B was tested by inoculating potential hosts from the families Cruciferae, Leguminosae, and

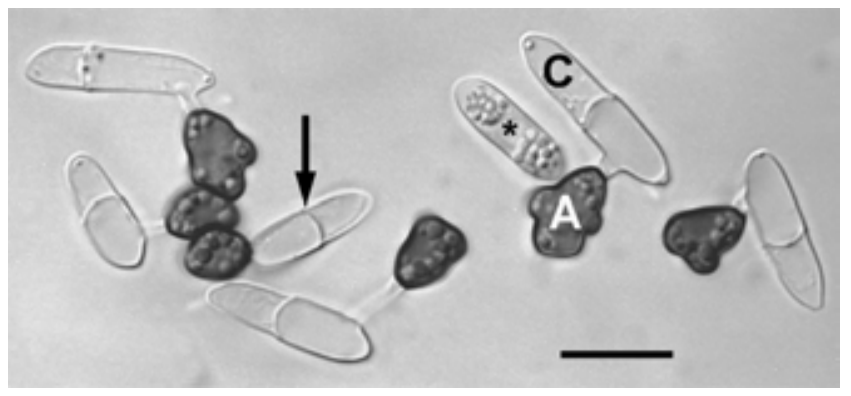

Fig. 1. Light micrograph showing conidia (C) of Colletotrichum destructivum isolate IMI 349061 germinating on polystyrene to form irregularly-shaped, melanized appressoria (A). Ungerminated conidia (asterisk) are unicellular, but become septate upon germination (arrow). Bar $=10 \mu \mathrm{m}$.

Table 1. Origins of the Colletotrichum isolates used in this study and the reference isolates used for ITS ribosomal DNA sequence comparisons

\begin{tabular}{|c|c|c|c|c|}
\hline Culture collection numbers & Colletotrichum sp. & Host plant & Country of origin & EMBL accession no. \\
\hline \multicolumn{5}{|l|}{ Isolates used } \\
\hline IMI 349061 & C. higginsianum ${ }^{\mathrm{a}}$ & Brassica campestris & Trinidad & AJ 558109 \\
\hline IMI $349063 \mathrm{~A}^{\mathrm{b}}$ & C. higginsianum ${ }^{\mathrm{a}}$ & B. campestris & Trinidad & AJ 558110 \\
\hline IMI $349063 B^{b}$ & C. higginsianum ${ }^{\mathrm{a}}$ & B. campestris & Trinidad & AJ 558111 \\
\hline LARS 056/IMI 334960 & C. destructivum & Vigna unguiculata & Nigeria $^{c}$ & AJ 558108 \\
\hline LARS 202/CBS 511.97 & C. destructivum & Medicago sativa & Morocco $^{\mathrm{d}}$ & AJ 558106 \\
\hline LARS 709/CBS 520.97 & C. destructivum & M. sativa & Saudi Arabia $^{\mathrm{d}}$ & None \\
\hline \multicolumn{5}{|l|}{ Reference isolates } \\
\hline LARS 319/A 22 & C. destructivum & M. sativa & Canada $^{\mathrm{d}}$ & AJ 558107 \\
\hline ATCC 10921 & C. destructivum & Nicotiana tabacum & Canada $^{\mathrm{e}}$ & AF 320562 \\
\hline ATCC 11995 & C. destructivum & N. tabacum & Canada $^{\mathrm{e}}$ & AF 320563 \\
\hline N150 & C. destructivum & N. tabacum & Canada $^{\mathrm{e}}$ & AF 320564 \\
\hline UQ343 & C. destructivum & Lens culinaris & Australia & AF 451908 \\
\hline MAFF 305635 & C. higginsianum & B. rapa & $\operatorname{Japan}^{\mathrm{f}}$ & AB 042302 \\
\hline CH90-M1 & C. higginsianum & Matthiola incana & $\operatorname{Japan}^{\mathrm{f}}$ & AB 042303 \\
\hline Cha-s & C. acutatum & Fragaria $\times$ ananassa & France & AF 489564 \\
\hline $\mathrm{CG} \mathrm{C} 2$ & C. gloeosporioides & Citrus sp. & South Africa & AF 289234 \\
\hline 99003 & C. graminicola & Agrostis palustris & Canada & AY 188926 \\
\hline CBS 151.28 & C. lindemuthianum & Phaseolus vulgaris & Germany & AJ 301946 \\
\hline
\end{tabular}

\footnotetext{
${ }^{a}$ Name as provided by CABI Bioscience.

b IMI 349063 was found to comprise two distinct isolates, designated 349063A and 349063B.

c Bailey et al. (1990).

${ }^{\mathrm{d}}$ Latunde-Dada et al. (1996; 1997).

e Shen et al. (2001).

${ }^{\mathrm{f}}$ Moriwaki et al. (1997).
} 
Solanaceae. Species were selected to include reported hosts of C. destructivum and C. higginsianum, as well as three different species of Arabidopsis. For each species-isolate combination, the disease reaction score was assessed after 4 days of incubation at $25^{\circ} \mathrm{C}$, on the basis of visible symptoms and microscopic examination of the extent of fungal development and host responses (Table 2). Five plants were scored for each combination in two separate inoculation experiments. The host range and pathogenicity of the three isolates were identical (Table 2). The only members of the family Cruciferae that were completely resistant to $C$. destructivum were Cardamine hirsuta and $C$. pratensis. All other species supported extensive fungal colonization and the production of conidia in acervuli and, therefore, were considered to be susceptible (disease reaction scores 3 or 4). However, the infection of Arabidopsis lasiocarpa, B. napus, B. oleracea, and species of Raphanus, Sinapis, and Capsella was associated with strong host responses in the form of localized necrosis or browning and cell wall thickenings, and acervuli were produced only sparsely (disease reaction score 3). Among members of the family Leguminosae, only lentil (Lens culinaris) and cowpea (Vigna unguiculata) were susceptible. Two species of Nicotiana both were resistant.
The pathogenicity of $C$. destructivum on A. thaliana was assessed using 15 accessions originating from different geographical regions and possessing resistance to a range of biotrophic pathogens, including Albugo, Erysiphe, Peronospora, and Phytophthora spp. The disease reaction score was assessed in seedlings and mature plants after 4 days of incubation at $25^{\circ} \mathrm{C}$. Responses to the three Brassica isolates of $C$. destructivum were identical. All the accessions were highly susceptible (disease reaction score 4), with the exception of Can-0, which gave a strong host response (disease reaction score 3 ). In young seedlings, no macroscopic symptoms were visible until $66 \mathrm{~h}$ after inoculation, when the hypocotyls started to collapse, and by $96 \mathrm{~h}$ all tissues were macerated and water soaked (Fig. 4B). Disease symptoms did not appear on mature plants until $96 \mathrm{~h}$ after inoculation, when the leaves became chlorotic and displayed small, discrete, water-soaked lesions (Fig. 4C). The lesions eventually coalesced, resulting in the death of individual leaves or the entire plant.

To determine the involvement of Arabidopsis defense pathways in restricting disease development, three A. thaliana signaling mutants were tested for their susceptibility toward $C$. destructivum isolate IMI 349061. These included NahG trans-

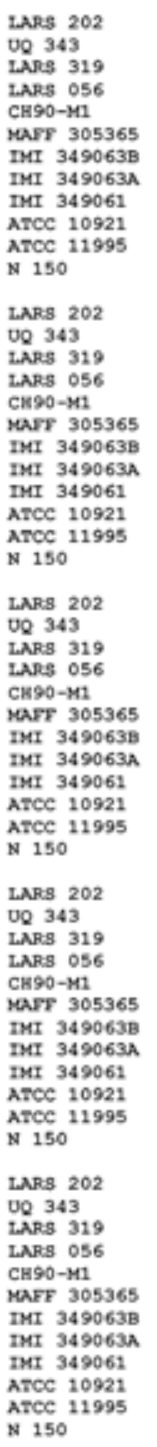

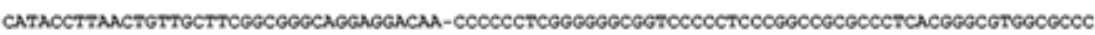

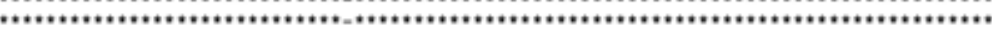

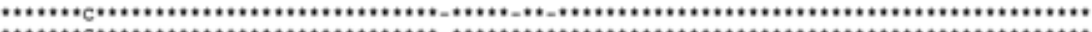

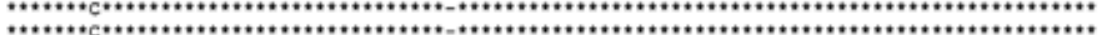

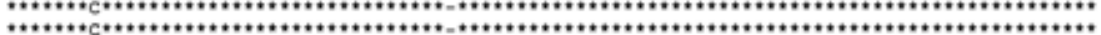

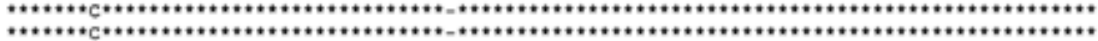

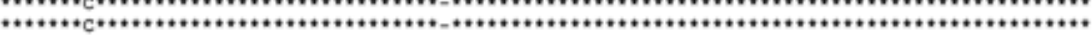

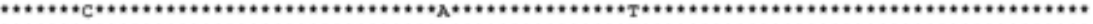

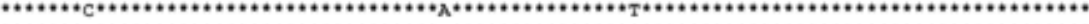

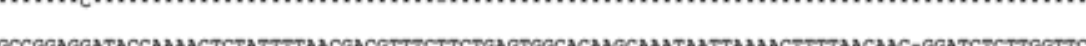
GCCGGAGGTACCAUACTCTATTTTAACGACGTTTCTTCTGAGTGGCACAMCNAATMATTAAACTTTTANCAA-GGATCTCTTGGTTC ,

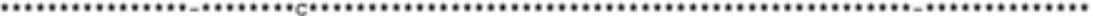

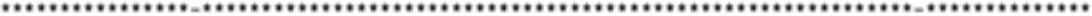
*

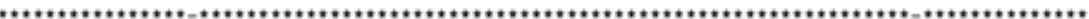

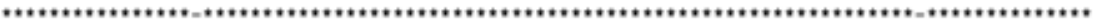

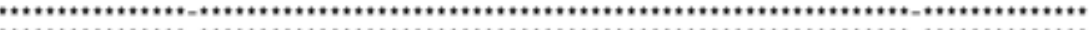
*n+k*t) *t.

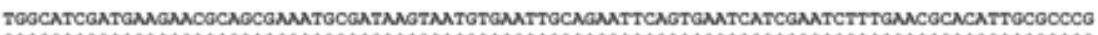

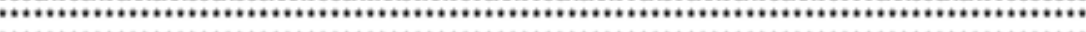

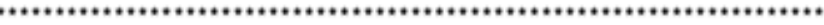
n   …………   Wwo n.

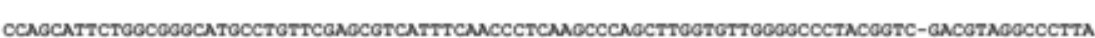
n.t. *  (1) .

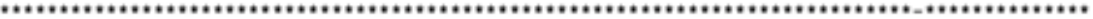
$x_{2}$

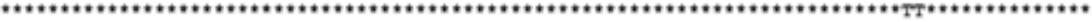

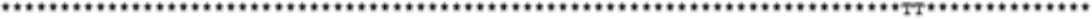

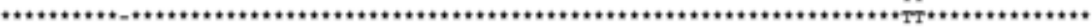

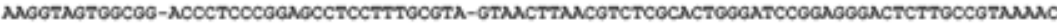

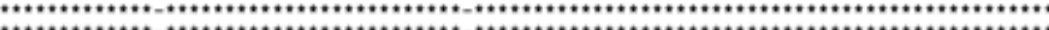
(1, *t,

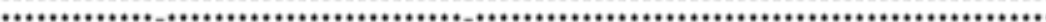

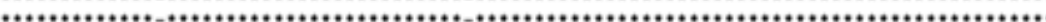
.

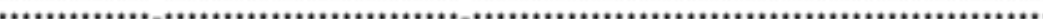

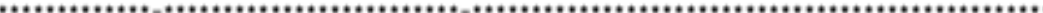

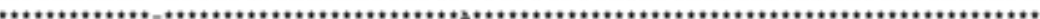

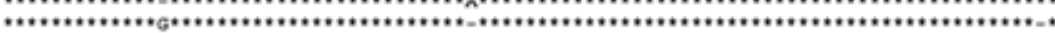

Fig. 2. Aligned sequences of the internal transcribed spacer (ITS)1, 5.8S RNA gene and ITS2 of the three Colletotrichum higginsianum isolates used in this study (IMI 349061, IMI 349063A, and IMI 349063B) together with reference isolates of C. destructivum (LARS 056, LARS 202, LARS 709, LARS 319, ATCC 10921, ATCC 11995, N150, and UQ343) and C. higginsianum (MAFF 305635 and CH90-M1). An asterisk indicates identity with the first sequence and a dash indicates an introduced gap. The alignment was generated using CLUSTAL W (Thompson et al. 1994). 
genic plants, expressing a bacterial salicylic acid (SA)-degrading enzyme (Delaney et al. 1994), the jasmonate-insensitive mutant coil (Feys et al. 1994), and the ethylene-insensitive mutant ein2-1 (Guzmann and Ecker 1990). All the mutants were in the genetic background of accession Col-0. For these experiments, we used 4-week-old plants, which were less susceptible to $C$. destructivum than young seedlings. NahG transgenic plants (Fig. 4E) and plants of the ein2-1 mutant (Fig. 4F) showed a hypersusceptible phenotype, in which many leaves died and became macerated, whereas symptoms were less severe in plants of the coil mutant (Fig. 4D), resembling those of the wild type (Fig. 4C). Thus, both the SA and ethylene signaling pathways appear to be important for limiting the colonization of Arabidopsis tissues by $C$. destructivum.

\section{Incompatible interactions between Arabidopsis and Colletotrichum spp.}

All A. thaliana accessions tested in this study were susceptible to the Brassica isolates of $C$. destructivum at $25^{\circ} \mathrm{C}$. However, one accession, Ws-2, showed resistance to these isolates when the inoculated plants were incubated at $15^{\circ} \mathrm{C}$. After $96 \mathrm{~h}$ at this temperature, seedlings of Ws-2 were completely symptomless (Fig. 4A), unlike those of other accessions, which had collapsed (Fig. 4B). Microscopic examination of hypocotyl tissues showed that small, peg-like hyphae first became visible within epidermal cells after $48 \mathrm{~h}$ at $15^{\circ} \mathrm{C}$ (Fig. 4G). When the tissue was treated with $0.85 \mathrm{M} \mathrm{KNO}_{3}$, the penetrated epidermal cells failed to plasmolyze, whereas adjacent uninfected cells plasmolyzed normally (Fig. 4G). Failure to plasmolyze is considered to be a reliable marker of irreversible damage to the plasma membrane and cell death (Bennett et al. 1996). Thus, single host cells appeared to undergo a hypersensitive response (HR) very soon after initial penetration by $C$. destructivum. Examination of fixed, cleared tissues at $72 \mathrm{~h}$ after inocu- lation (i.e., approximately $24 \mathrm{~h}$ after penetration) showed that the granulated cytoplasm of HR cells stained strongly with Aniline blue, while that of uninfected cells was unstained (Fig. $4 \mathrm{H})$. At this stage, the hyphae inside HR cells were very small and, in many cases, no hypha was visible beneath the darkly melanized appressorium. A localized accumulation of hydrogen peroxide was detected in the cytoplasm and walls of HR cells by staining with diaminobenzidine (Fig. 4I). Although hyphae continued to grow slowly within the HR cells, they did not go on to colonize any further cells. In seedling tissues, the HR rarely extended beyond one epidermal cell; however, in the leaves of mature plants, a variable number of surrounding uninfected epidermal and mesophyll cells also died and collapsed (data not shown).

Two isolates of $C$. destructivum originating from alfalfa (LARS 709 and LARS 202) and one from cowpea (LARS 056) produced appressoria with visible penetration pores on seedlings of $A$. thaliana accessions Col-0, Ler-0, and Ws- 2 . However, no infection hyphae were seen in any of these isolateaccession combinations after 7 days of incubation at either 15 or $25^{\circ} \mathrm{C}$. Epidermal cells responded to attempted fungal penetration by depositing papillae, which fluoresced bright yellowblue after staining with Aniline blue (Fig. 4J), indicating the presence of callose. An HR was not seen in any of these nonhost interactions.

\section{Compatible interaction \\ between Arabidopsis and Colletotrichum spp.}

All aerial parts of $A$. thaliana plants were susceptible to infection by $C$. destructivum, including hypocotyls, cotyledons, rosette and cauline leaves, flowering stems, sepals, petals, and siliques. There were no significant cytological differences between any of the isolate-accession combinations and, unless otherwise stated, all the images presented here illustrate isolate

Table 2. Host range of three Brassica isolates of Colletotrichum destructivum

\begin{tabular}{|c|c|c|c|c|}
\hline \multirow[b]{2}{*}{ Family, genus, species } & \multirow[b]{2}{*}{ Common name or cultivar } & \multicolumn{3}{|c|}{ Disease reaction score of isolates ${ }^{a}$} \\
\hline & & IMI 349061 & IMI 349063A & IMI 349063B \\
\hline \multicolumn{5}{|l|}{ Cruciferae } \\
\hline Arabidopsis griffithiana & $\ldots$ & 4 & 4 & 4 \\
\hline A. lasiocarpa & $\ldots$ & 3 & 3 & 3 \\
\hline A. thaliana & Thale Cress, accession Col- 0 & 4 & 4 & 4 \\
\hline Arabis alpina & Alpine Rockcress & 4 & 4 & 4 \\
\hline Brassica napus & Swede (cv. Garden Purple Top Acme) & 4 & 4 & 4 \\
\hline B. napus & Oil-seed rape (cv. Apex) & 3 & 3 & 3 \\
\hline B. oleracea var. capitata & Cabbage (cv. Flowers of Spring) & 3 & 3 & 3 \\
\hline B. campestris subsp. rapifera & Turnip (cv. Snowball) & 4 & 4 & 4 \\
\hline B. campestris subsp. chinensis & Pak-choi & 4 & 4 & 4 \\
\hline Capsella bursa-pastoris & Shepherd's Purse & 3 & 4 & 4 \\
\hline Cardamine hirsuta & Hairy Bittercress & 1,2 & 1,2 & 1,2 \\
\hline C. pratensis & Cuckoo Flower & 1 & 1 & 1 \\
\hline Raphanus sativus & Radish (cv. Scarlet Globe) & 3 & 3 & 3 \\
\hline Sinapis alba & White mustard & 3 & 3 & 3 \\
\hline \multicolumn{5}{|l|}{ Leguminosae } \\
\hline Glycine $\max$ & Soybean & 1,2 & 1,2 & 1,2 \\
\hline Lens culinaris & Brown lentil & 4 & 4 & 4 \\
\hline Medicago sativa & Lucerne (cv. Saranac) & 0 & 0 & 0 \\
\hline M. truncatula & Barrel medick, accession J6 & 2 & 2 & 2 \\
\hline Trifolium repens & White clover (cv. Arran) & 0 & 0 & 0 \\
\hline Vicia faba & Broad bean & 1 & 1 & 1 \\
\hline Vigna unguiculata & Cowpea (cv. Blackeye) & 3 & 3 & 3 \\
\hline \multicolumn{5}{|l|}{ Solonaceae } \\
\hline Nicotiana glutinosa & Tobacco & 1,2 & 1,2 & 1,2 \\
\hline N. tabacum & Tobacco cv. Xanthi & 1,2 & 1,2 & 1,2 \\
\hline
\end{tabular}

${ }^{a}$ Disease reaction scores (assessed after 4 days of incubation at $25^{\circ} \mathrm{C}$ ): $0=$ no symptoms; appressoria present but no visible infection hyphae or host response; 1 = no symptoms; appressoria present but penetration blocked by papillae; 2 = no symptoms; single-cell hypersensitive response; infection hyphae confined to one or two dead host cells; 3 = brown necrotic flecks or small limited lesions; extensive host cell necrosis, host wall appositions, or both, fungal development restricted but some acervuli present; 4 = spreading, water-soaked lesions; tissue macerated and packed with fungal mycelium; acervuli abundant. 


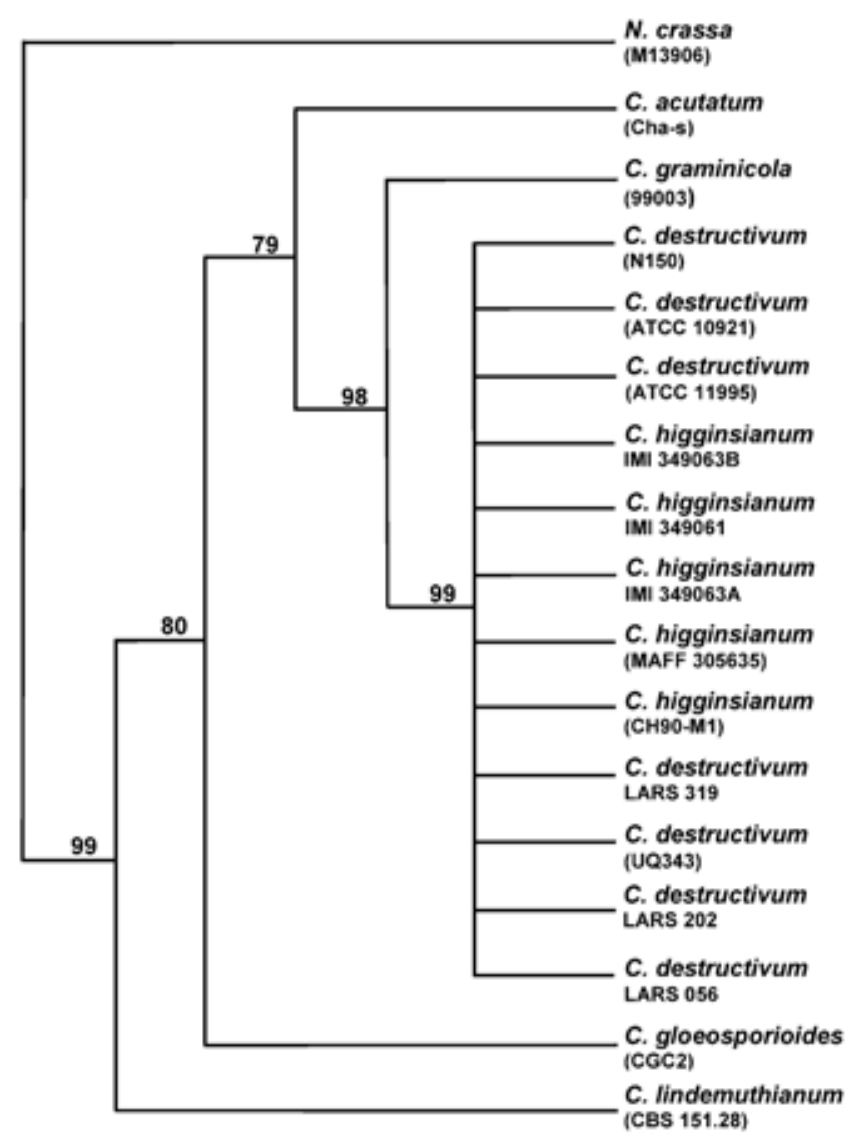

Fig. 3. Parsimony consensus tree prepared using PHYLIP software, based on internal transcribed spacer sequences, depicting the relationship of the three Colletotrichum higginsianum isolates used in this study (IMI 349061, IMI 349063A, and IMI 349063B) with reference isolates of $C$. higginsianum, C. destructivum, and other Colletotrichum spp. representing the diversity of the genus. The tree was prepared from 100 bootstrap data sets using the jumble option. Only bootstrap values over $75 \%$ are presented, other groups being collapsed to the previous node. Neurospora crassa was included as an outgroup.
IMI 349061 infecting hypocotyls or cotyledons of accession Ler- 1 at $25^{\circ} \mathrm{C}$. Infection proceeded more rapidly at this temperature than at $15^{\circ} \mathrm{C}$, and small, intracellular hyphae first became visible within hypocotyl epidermal cells at $18 \mathrm{~h}$. These branched and expanded to form large-diameter $(4.5$ to $8.5 \mu \mathrm{m})$ primary hyphae by $24 \mathrm{~h}$ (Fig. 4K). Primary hyphae eventually packed the first infected epidermal cell but never developed beyond it. Narrower secondary hyphae $(2.2$ to $4.0 \mu \mathrm{m})$ began to emerge from the primary hyphae at $48 \mathrm{~h}$, and these penetrated the host cell wall to invade surrounding cells (Fig. 4L). By $55 \mathrm{~h}$, host tissues were extensively colonized by a dense mycelium of intra- and intercellular hyphae, which extended from the upper to the lower epidermis of cotyledons. By $72 \mathrm{~h}$, the asexual cycle was completed with the production of abundant acervuli on the surface of the dead host tissue. These consisted of conidial masses produced from a cluster of short conidiophores, through which one or two long, melanized setae protruded (Fig. 4M). The infection of rosette leaves in mature A. thaliana plants progressed more slowly than in seedlings because the initial penetration of epidermal cells took longer. Thus, at a temperature of $25^{\circ} \mathrm{C}$, primary hyphae and secondary hyphae were first seen at 48 and $72 \mathrm{~h}$, respectively.

To test whether host cells were alive during the early stages of infection, hypocotyl tissue was plasmolyzed in $0.85 \mathrm{M}$ $\mathrm{KNO}_{3}$ containing Neutral Red. At 18 to $24 \mathrm{~h}$, epidermal cells containing primary hyphae plasmolyzed normally and accumulated the vital dye in their vacuoles (Fig. 4N), indicating that, at this stage, the plasma membrane and tonoplast retained their structural and functional integrity. However, by the time secondary hyphae began to develop at $42 \mathrm{~h}$, infected cells failed to plasmolyze or stain with Neutral Red and appeared to be dead (Fig. 4O). To determine whether the hyphae of $C$. destructivum expressed an antigen homologous to the biotrophyrelated glycoprotein, $\mathrm{CIH} 1$, identified in the bean anthracnose pathogen, C. lindemuthianum (Perfect et al. 2000), infected epidermal strips were labeled by immunofluorescence with monoclonal antibody UB25. Antigens cross-reacting with UB25 were detected on the surface of the primary hyphae of C. destructivum (Fig. 4P), but secondary hyphae were not labeled, even where they were present in the same host cell as primary hyphae (results not shown). The control antibody, UBIM22, did not label any fungal structures. The primary

Fig. 4. Infection of Arabidopsis thaliana by Colletotrichum destructivum. A, B, Symptoms on 12-day-old seedlings incubated for $96 \mathrm{~h}$ at $15^{\circ} \mathrm{C}$. Seedlings of $\mathbf{A}$, accession Ws-2 are symptomless, whereas seedlings of $\mathbf{B}$, accession Ler-0 are completely collapsed and macerated. $\mathbf{C}$ through $\mathbf{F}$, Symptoms on 4-weekold plants incubated for $96 \mathrm{~h}$ at $25^{\circ} \mathrm{C}$. The leaves of $\mathbf{C}$, a mature, wild-type plant of Col-0 show large areas of chlorosis and small, dark, water-soaked lesions. E, NahG transgenic plants and $\mathbf{F}$, plants of the ein2-1 mutant show a hypersusceptible phenotype, in which many leaves are completely collapsed and macerated. D, Plants of the coil mutant show less severe symptoms resembling those of the wild type. G through I, Light micrographs showing the hypersensitive response of A. thaliana accession Ws-2 to an isolate of C. destructivum from Brassica (IMI 349061) when inoculated seedlings are incubated at $15^{\circ} \mathrm{C}$. G, An appressorium (A) penetrating a hypocotyl epidermal cell to form a small intracellular hypha (arrow), $48 \mathrm{~h}$ after inoculation. The infected cell has failed to plasmolyze in $0.85 \mathrm{M} \mathrm{KNO}_{3}$ whereas the adjacent uninfected cell has plasmolyzed normally. Arrowheads $=$ plasma membrane, $\mathrm{C}=$ conidium, bar $=10 \mu \mathrm{m}$. H, Hypocotyl tissue cleared and stained with lactophenol-Aniline blue, $72 \mathrm{~h}$ after inoculation. A penetrated epidermal cell has granulated cytoplasm and is stained more strongly by Aniline blue than the surrounding uninfected cells. Hyphae are too small to be visible beneath the melanized appressoria (arrows). Bar $=20 \mu \mathrm{m}$. I, Cotyledon tissue stained with diaminobenzidine to detect $\mathrm{H}_{2} \mathrm{O}_{2}, 96 \mathrm{~h}$ after inoculation. The cell wall and contents of a penetrated epidermal cell are strongly stained while adjacent uninfected cells are unstained. Arrow $=$ hypha, bar $=20 \mu \mathrm{m}$. J, Epifluorescence micrograph showing the papilla response of $A$. thaliana accession Ws-2 to penetration by an isolate of $C$. destructivum from cowpea (LARS 056). Inoculated tissue was incubated at $25^{\circ} \mathrm{C}$ for $48 \mathrm{~h}$ and stained with Aniline blue to detect callose. Papillae in a cotyledon epidermal cell fluoresce brightly, except where obscured by melanized appressoria. Bar $=20 \mu \mathrm{m}$. K through $\mathbf{P}$, Cytology of the compatible interaction between seedlings of $A$. thaliana accession Ler-0 and $C$. destructivum isolate IMI 349061, incubated at $25^{\circ} \mathrm{C}$. Bars $=10 \mu \mathrm{m}$. K. Appressorium (A) penetrating a hypocotyl epidermal cell to form a large primary hypha ( $\mathrm{PH})$. Stained with lactophenol-Aniline blue, $24 \mathrm{~h}$ after inoculation. Note the narrow neck region (arrow). L, Confocal micrograph showing colonization of hypocotyl tissue by $C$. destructivum transformant D3, which expresses green fluorescent protein constitutively, 55 h after inoculation. Note narrow secondary hyphae (arrowheads) emerging from the larger primary hyphae (arrows). Chloroplast autofluorescence appears red. M, Acervuli on the surface of dead cotyledon tissues. Conidia (arrowheads) are produced from short conidiophores (asterisks). Note the melanized seta (arrow). Stained with lactophenol-Aniline blue, $72 \mathrm{~h}$ after inoculation. N, A hypocotyl epidermal cell containing a primary hypha (PH) has plasmolyzed normally in $0.85 \mathrm{M}$ $\mathrm{KNO}_{3}$ and accumulated the vital dye Neutral Red in its vacuole (V). Arrowheads = plasma membrane; $24 \mathrm{~h}$ after inoculation. O, Infected epidermal cells do not plasmolyze or accumulate Neutral red by the time secondary hyphae (arrows) emerge from the primary hyphae (PH), at $55 \mathrm{~h}$ after inoculation. $\mathbf{P}$, Immunofluorescence labeling of primary hyphae inside a leaf epidermal cell with monoclonal antibody UB25, specific for the Colletotrichum biotrophyrelated protein $\mathrm{CIH} 1,24 \mathrm{~h}$ after inoculation. 


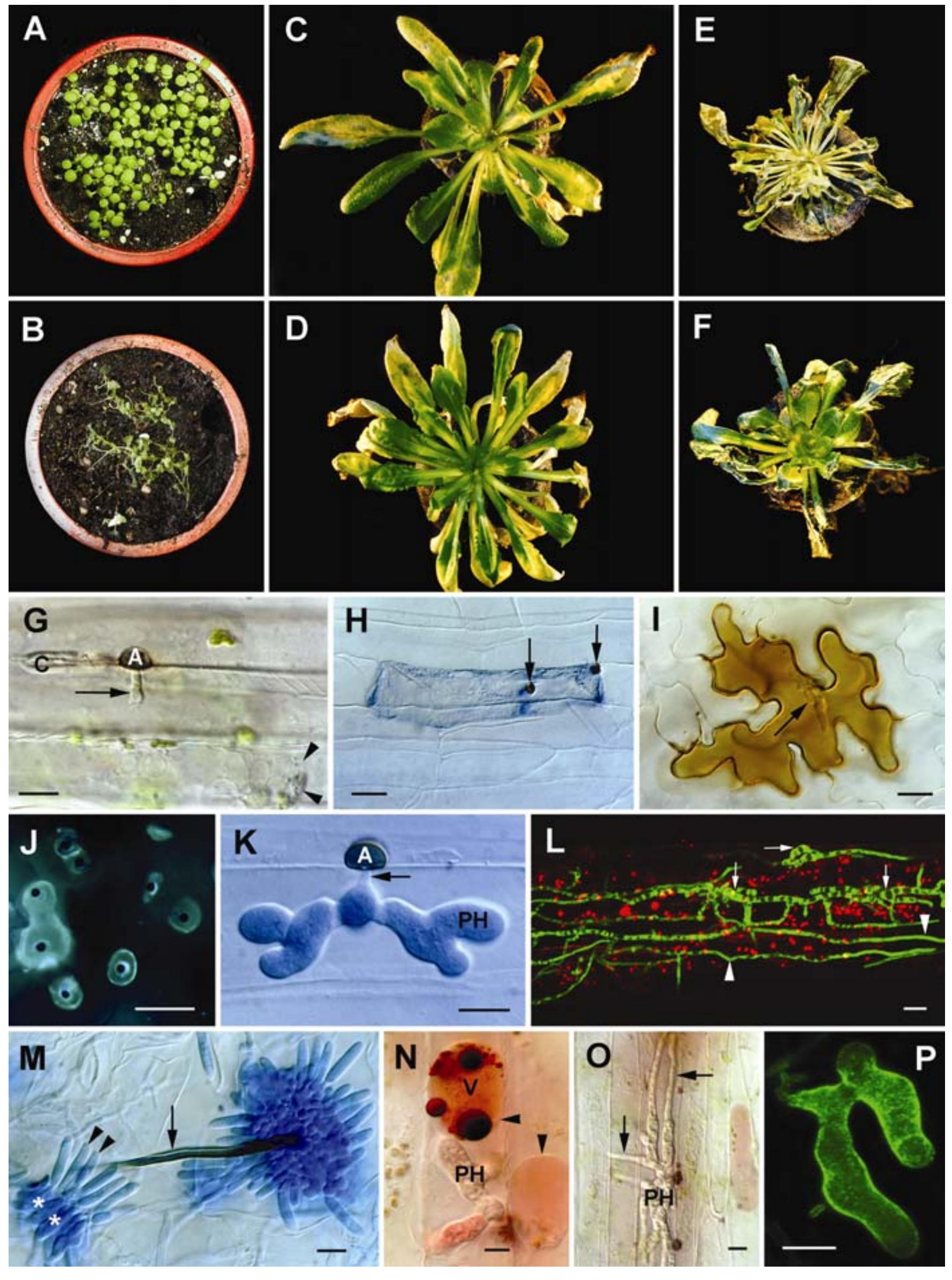


hyphae of $C$. destructivum isolate LARS 202 also expressed CIH1 during infection of alfalfa (Perfect et al. 2000).

Electron microscopy (EM) was used to examine the ultrastructure of the plant-fungal interface. An infection peg emerged through a pore in the base of the appressorium and penetrated host cells directly (Fig. 5A and B). There was no visible degradation of the host cuticle or epidermal cell wall around the infection peg (Fig. 5B). A small pad of host wall apposition material was deposited at the site of initial penetration but this did not restrict fungal development (Fig. 5B). Before expanding to form primary hyphae, the infection peg elongated several microns into the cell lumen, forming a narrow "neck" $(1.8 \mu \mathrm{m}$ in diameter $)$ that contained a single septum (Fig. 5A and C). The cytoplasm of epidermal cells invaded by primary hyphae initially retained normal ultrastructure; the thin layer of peripheral host cytoplasm and the host plasma membrane becoming invaginated around the fungus (Fig. 5A and C). The hyphal wall appeared to make close contact with the host plasma membrane, with no interfacial matrix separating them (Fig. 5C). By the time secondary hyphae appeared, the cytoplasm of the first infected epidermal cell was completely disrupted, and all other host cells in contact with secondary hyphae also appeared empty of cytoplasm (Fig. 5D). Host cell walls adjoining secondary hyphae lost their affinity for EM stains, suggesting they were degraded by fungal enzymes, but the cuticle remained intact, even where the underlying wall was completely degraded (Fig. 5D).

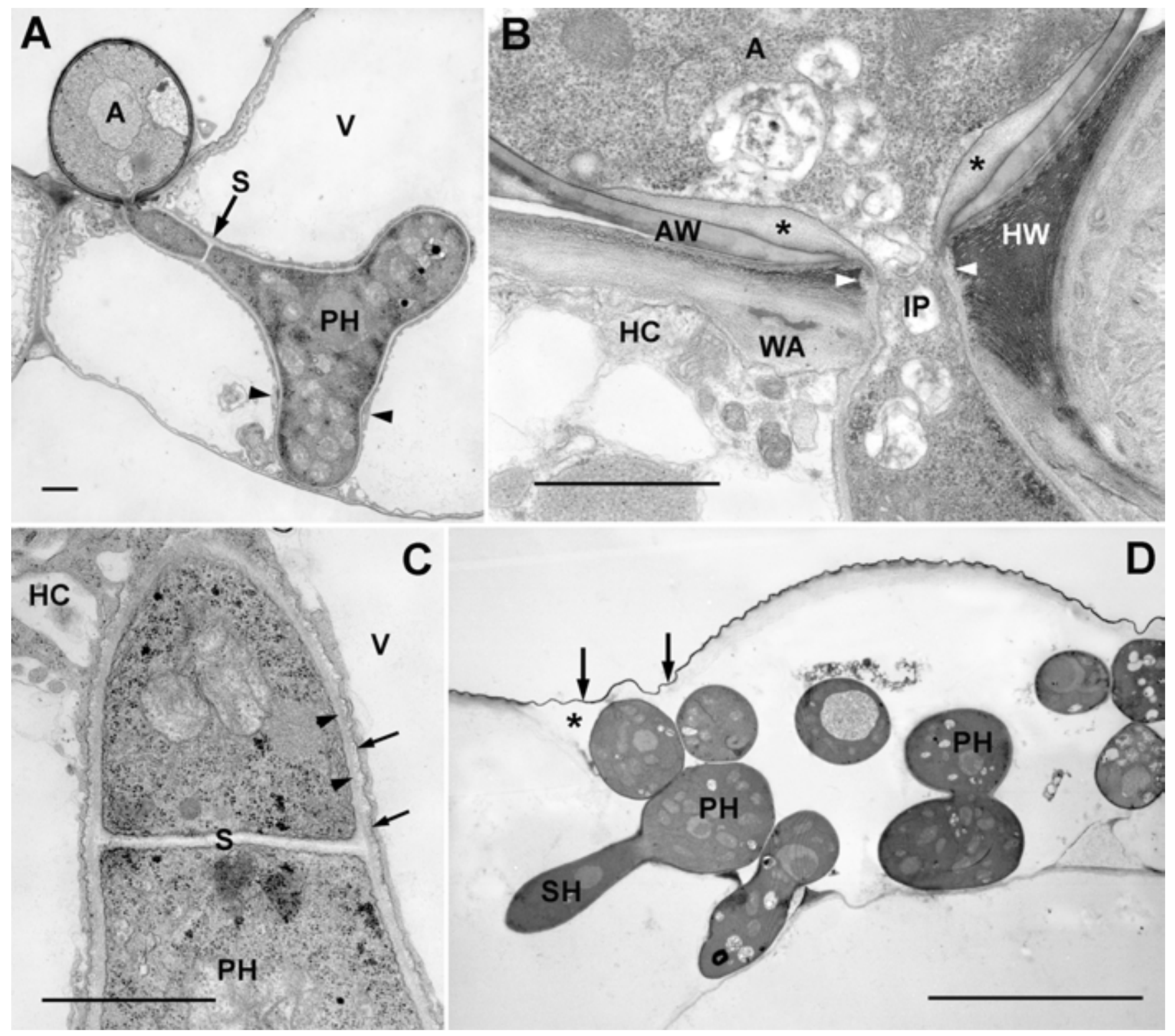

Fig. 5. Transmission electron microscopy images of the compatible interaction between Arabidopsis thaliana accession Ler-0 and Colletotrichum destructivum isolate IMI 349061. Hypocotyl tissue was incubated at $25^{\circ} \mathrm{C}$ for $\mathbf{A}, \mathbf{B}$, and $\mathbf{C}, 24 \mathrm{~h}$ or $\mathbf{D}, 72 \mathrm{~h} . \mathrm{V}=$ vacuole; $\mathrm{S}=$ septum; HC $=$ host cytoplasm. A, The appressorium (A) has penetrated a host epidermal cell to form a primary hypha ( $\mathrm{PH}$ ). The thin peripheral layer of host cytoplasm has invaginated around the hypha (arrowheads). Bar $=1 \mu \mathrm{m}$. B, Site of initial penetration, showing part of an appressorium (A) and infection peg (IP). The outer layer of the appressorial wall (AW) is more electron-opaque than the inner layer, while a third wall layer (asterisks) forms a thickened ring around the penetration pore, continuous with the infection peg wall. There is no visible degradation of the host cell wall (HW) around the infection peg (arrowheads). A small host wall apposition (WA) is present at the site of penetration. Bar $=1 \mu \mathrm{m}$. C, Neck region of a primary hypha (PH), showing the absence of an interfacial matrix between the fungal cell wall (arrowheads) and the invaginated host plasma membrane (arrows). Bar $=1 \mu \mathrm{m}$. D, Host epidermal cell packed with large primary hyphae $(\mathrm{PH})$, from which narrower secondary hyphae $(\mathrm{SH})$ are emerging to colonize adjacent cells. The cytoplasm of all infected cells is destroyed and host cell walls are degraded (asterisk), but the host cuticle (arrows) remains intact. Bar $=10 \mu \mathrm{m}$. 
Agrobacterium-mediated transformation of $C$. destructivum.

Agrobacterium tumefaciens-mediated transformation (ATMT) has been applied successfully to a growing number of filamentous fungi, including C. gloeosporioides (de Groot et al. 1998; Mullins et al. 2001; Zwiers and de Waard 2001). The ability of ATMT to mutate fungal genes in either a random or targeted manner holds great potential for investigating gene function and the molecular basis of fungal pathogenicity (Mullins and Kang 2001). To explore the feasibility of this approach in $C$. destructivum, we used ATMT to introduce the $h p h$ (hygromycin resistance) and green fluorescent protein (GFP) marker genes into germinating conidia. Approximately 250 hygromycin-resistant transformants were obtained per $1 \times$ $10^{6}$ conidia. Five transformants (D1 to D5) were analyzed by Southern blotting, using the GFP coding sequence as a probe, to determine the number of gene insertions. Two transformants had single-copy T-DNA insertions whereas the others had integrated three copies of the transgene (results not shown). All five transformants grew normally and were as pathogenic as the wild type, and the expression of GFP was stable after repeated subculture of the transformants on nonselective medium (i.e., lacking hygromycin). Transformant D3 showed the highest level of fluorescence emission and was selected for cytological studies. The constitutive expression of GFP in this transformant allowed fungal development in planta to be monitored noninvasively using epifluorescence or confocal microscopy. The fungal cytoplasm fluoresced brightly in all actively growing fungal structures produced during the infection of Arabidopsis thaliana, including primary and secondary hyphae (Fig. 4L), but GFP fluorescence was attenuated by the melanized cell walls of appressoria and setae (results not shown).

\section{DISCUSSION}

In this article, we show for the first time that a species of Colletotrichum is able to infect and complete its asexual cycle on A. thaliana. The isolates used in this study were provided under the name $C$. higginsianum, which causes anthracnose leaf spot disease on a wide range of cruciferous plants in South Atlantic and Gulf states of the United States, the West Indies, Japan, and southeast Asia (Higgins 1917; Moriwaki et al. 1997; Scheffer 1950; Sutton 1980). However, the taxonomic status of $C$. higginsianum is open to question. It was regarded as a synonym of $C$. gloeosporioides by von Arx (1957) but more recently has been recognized as a distinct species on the basis of its conidial morphology and consistent association with cruciferous hosts (Sutton 1980, 1992), and analysis by arbitrarily primed polymerase chain reaction (Moriwaki et al. 1997). Analysis of the ITS1, 5.8S RNA gene and ITS2 regions of the $C$. higginsianum isolates used in the present study showed them to be closely related to $C$. destructivum. The size and morphology of their conidia and appressoria were entirely consistent with the description of $C$. destructivum provided by Sutton (1992), and the conidia of isolate IMI 349063A also were below the size range given by this author for $C$. higginsianum. Moreover, the infection process closely resembled the behavior of $C$. destructivum on cowpea, alfalfa, and tobacco (Latunde-Dada et al. 1996, 1997; Shen et al. 2001). In particular, the production of large, swollen primary hyphae with narrow neck regions in single host epidermal cells is a characteristic feature of $C$. destructivum (Latunde-Dada et al. 1997). Taken together, our results indicate that the isolates used in the present study should be regarded as $C$. destructivum. However, the analysis of a larger collection of $C$. higginsianum and $C$. destructivum isolates, preferably based on a multilocus comparison (e.g., of ITS, tub2, and his4) (Talhinhas et al. 2002), is required before the species or subspecies status of the two taxa confidently can be resolved.

C. destructivum has a wide host range that includes many legumes (e.g., cowpea, soybean, and alfalfa), solanaceous plants (e.g., tobacco), and dodder (Cuscuta spp.) (LatundeDada et al. 1997; Shen et al. 2001). The present study demonstrated that many cruciferous plants also can act as hosts to this pathogen, including species of Arabidopsis. It remains unclear whether natural infections of $A$. thaliana by $C$. destructivum occur in those geographical regions where both organisms are present, such as Japan and North America. Interestingly, different isolates of $C$. destructivum showed host specificity. For example, Brassica isolates could infect cowpea but not tobacco or alfalfa, while cowpea and alfalfa isolates were unable to infect $A$. thaliana. Thus, $C$. destructivum could provide an excellent model for studying the molecular basis of pathogenic specialization toward different host plants.

The infection of $A$. thaliana tissues by $C$. destructivum followed the two-stage, hemibiotrophic pattern typical of other Colletotrichum spp., with dimorphic primary and secondary hyphae (O'Connell et al. 1985, 1993; Wharton et al. 2001). Plasmolysis and vital staining experiments showed that host epidermal cells initially survived penetration by primary hyphae, and this was confirmed by transmission electron microscopy (TEM) of the infected cells, which showed that an intact host plasma membrane was in ted around these structures. Together with the detection on primary hyphae of the biotrophy-related glycoprotein CIH1 (Perfect et al. 2000), these results suggest that, during this early stage of infection, the pathogen behaves as an intracellular biotroph, obtaining nutrients from living host cells. The initial biotrophic phase was brief ( 12 to $18 \mathrm{~h}$ ) and entirely confined to the first infected epidermal cell, as reported for $C$. destructivum attacking cowpea and tobacco (Bailey et al. 1990; Shen et al. 2001).

In a survey of a limited number of $A$. thaliana accessions, only Ws-2 showed resistance to $C$. destructivum. However, the

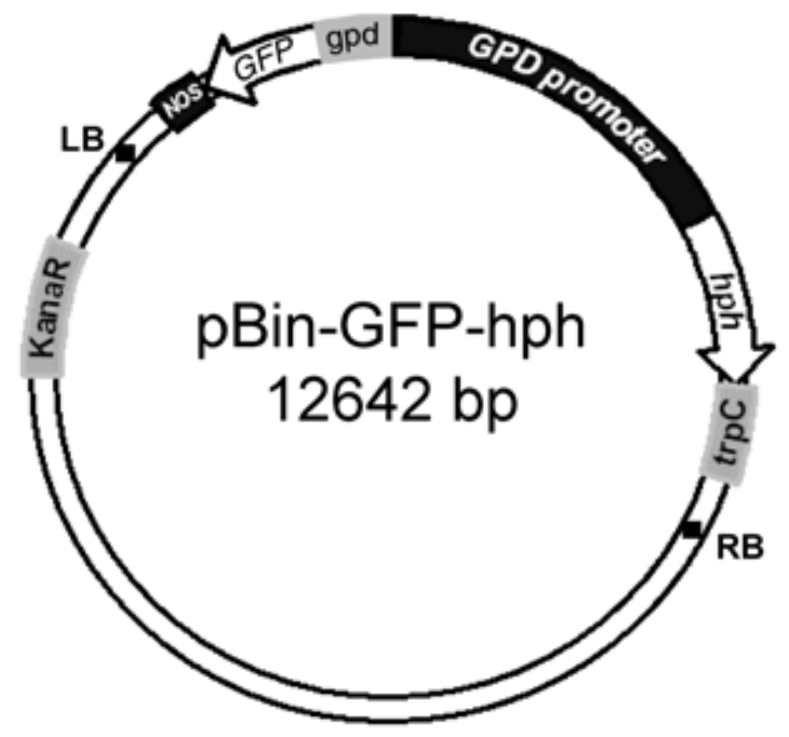

Fig. 6. Map of the pBin-GFP-hph vector used for Agrobacterium-mediated transformation of Colletotrichum destructivum. The SGFP-TYG gene (GFP; Chiu et al. 1996) fused to a 405-bp fragment of the GPDA promoter from Aspergillus nidulans (gpd; Herbert et al. 2002) and the NOS terminator was cloned into the pDHt vector (Mullins et al. 2001), along with a hygromycin resistance cassette containing the $h p h$ gene $(h p h)$ under the control of the complete GPD promoter (GPD) and the A. nidulans trpC terminator $(\operatorname{trp} C)$. KanaR = kanamycin resistance gene; $\mathrm{LB}=$ left border of the T-DNA; RB = right border of the T-DNA. 
expression of resistance in Ws-2 was affected by temperature: seedlings gave a rapid, single-cell $\mathrm{HR}$ at $15^{\circ} \mathrm{C}$, but were fully susceptible at $25^{\circ} \mathrm{C}$. Thermosensitive resistance responses have been described in several other plant species. In tobacco, the $N$ gene confers resistance to the Tobacco mosaic virus (TMV) at temperatures below $28^{\circ} \mathrm{C}$; whereas, at higher temperatures, the virus infects plants systemically. The $N$ gene mediates recognition of the helicase domain of TMV replicase proteins, leading to the induction of an HR and, in this case, thermosensitivity may be a property of the viral protein (Erikson et al. 1999). In the tomato-Cladosporium fulvum interaction, host defense responses mediated by the $R$ genes $C f-4$ and $C f-9$ are reversibly suppressed at elevated temperatures $\left(33^{\circ} \mathrm{C}\right)$. In this system, the thermosensitive component appears to be perception of the fungal avirulence elicitors (de Jong et al. 2002). Although the mechanism of thermosensitive resistance to Colletotrichum destructivum is unclear, the Arabidopsis model should allow rapid isolation of the plant genes involved.

Two mutants showing defects in the SA and ethylene pathways were found to be hypersusceptible to $C$. destructivum. Earlier studies suggested that the SA-dependant pathway was required for defense against biotrophic pathogens, whereas the ethylene and jasmonic acid pathways were effective against necrotrophic pathogens (Thomma et al. 2001a,b). From our study, it appears that a more complex network of defense pathways could be involved in resistance to hemibiotrophic pathogens, which behave as both biotrophs and necrotrophs at different stages of their development. The $C$. destructivumArabidopsis pathosystem provides a new tool to investigate how plants respond to these pathogens.

The efficient genetic transformation of $C$. destructivum was achieved by Agrobacterium-mediated transfer of T-DNA into germinating conidia. The transformation of tobacco isolates of this species by the electroporation of conidia was reported recently (Chen et al. 2003), and the transformation of several other Colletotrichum spp. by electroporation or protoplast/polyethylene glycol-based methods is well established (Redman and Rodriguez 1994; Robinson and Sharon 1999). However, ATMT has the major advantage that it avoids the problems associated with preparing fungal protoplasts (Mullins et al. 2001). The ATMT of one other Colletotrichum sp. (C. gloeosporioides) has been reported (de Groot et al. 1998), but the efficiency (130 transformants per $1 \times 10^{6}$ conidia) was approximately twofold lower than that obtained in the present study with $C$. destructivum. In fungi, as in other organisms, the T-DNA integrates at random into the recipient genome (de Groot et al. 1998; Mullins et al. 2001). This, together with the high frequency of transformation obtained in $C$. destructivum, opens up the possibility of preparing libraries of T-DNAtagged insertional mutants for the rapid identification of pathogenicity genes (Mullins and Kang 2001; Mullins et al. 2001). Agrobacterium-mediated transformation also can be used for the targeted disruption of selected fungal genes by homologous recombination (Zwiers and de Waard 2001), and this will be essential for testing gene function in C. destructivum.

In conclusion, a novel Arabidopsis-Colletotrichum pathosystem has been described in which both partners in the interaction can be genetically manipulated. The pathogen has an infection process similar to that shown by many other Colletotrichum spp., so that information obtained from the interaction with Arabidopsis spp. should be directly relevant to agronomically important anthracnose diseases on a wide range of crop plants. Furthermore, the intracellular primary hyphae of $C$. destructivum are the functional equivalent of haustoria; therefore, the pathosystem should provide valuable insights into the molecular basis of biotrophy in obligate organisms, such as the rusts, powdery mildews, downy mildews, and mycorrhizae, which are not readily amenable to cultivation and genetic manipulation. $C$. destructivum also could serve as a model for testing the function of genes isolated from these obligate biotrophs.

\section{MATERIALS AND METHODS}

\section{Plant cultivation.}

The Nottingham Arabidopsis Stock Centre (Nottingham, U.K.) supplied seed of Arabidopsis griffithiana, A. lasiocarpa, and the $A$. thaliana accessions C24, Can-0, Cnt-1, Co1, Col-0, Dra-1, Kas-1, Ksk-1, Ler-0, Ms-0, Nd-0, Rld-2, Wa-1, Wei-0, and Ws-2. The coil mutant was provided by John Turner (University of East Anglia, Norwich, U.K.) and seed of the ein2-1 mutant and the NahG transgenic line were obtained from Y. Marco (INRA, Toulouse, France). Seed of Cardamine and Capsella spp. were obtained from Herbiseed (Twyford, U.K.). Seed of all other species of Cruciferae, Leguminosae, and Nicotiana were obtained from Chiltern Seeds (Ulverston, Cumbria, U.K.), Nickerson Ltd. (Rothwell, Lincs, U.K.), and INRA (Toulouse, France). A. thaliana seed was sown on the surface of a peat-based compost and transferred to a growth chamber with a 16 -h photoperiod and day and night temperatures of 23 and $18^{\circ} \mathrm{C}$, respectively. To obtain slightly etiolated seedlings, a photosynthetic photon fluence rate (PPFR) of $80 \mu \mathrm{mol} \mathrm{m} \mathrm{m}^{-2} \mathrm{~s}^{-1}$ (400 to $700 \mathrm{~nm}$ ) was used. Plants of all other members of Cruciferae and species of Nicotiana, Trifolium, and Vicia were grown in a cool glasshouse ( 18 to $23^{\circ} \mathrm{C}$ day, 15 to $20^{\circ} \mathrm{C}$ night) with supplementary lighting from high-pressure sodium lamps (16-h photoperiod) and 65 to $80 \%$ relative humidity (RH). Glycine, Lens, Lotus, Medicago, and Vigna spp. were grown at $25^{\circ} \mathrm{C}$ in a growth chamber $(80 \% \mathrm{RH}, 16-\mathrm{h}$ photoperiod, and a PPFR of $\left.40 \mu \mathrm{mol} \mathrm{m}{ }^{-2} \mathrm{~s}^{-1}\right)$.

\section{Fungal culture and inoculation of plants.}

The origins of the Colletotrichum isolates used in this study are given in Table 1. Monoconidial cultures prepared from each isolate were grown on Mathur's agar medium at $17^{\circ} \mathrm{C}$ and subcultured using spore suspension, prepared from 7-dayold cultures (Sherriff et al. 1994). To produce appressoria in vitro, drops $(30 \mu \mathrm{l})$ of conidial suspension were placed on polystyrene petri dishes and incubated in a humid chamber at $25^{\circ} \mathrm{C}$. Arabidopsis seedlings were inoculated at 12 days after sowing, when the first two true leaves started to expand. Mature Arabidopsis plants were inoculated 4 to 5 weeks after sowing, at the start of flowering. Cultivars of Brassica, Raphanus, and Sinapis spp. were inoculated as 7-day-old seedlings. All other plant species were grown to the four- to six-leaf stage before inoculation. All plants were inoculated by spraying with conidial suspension $\left(1 \times 10^{6}\right.$ spores $\left.\mathrm{ml}^{-1}\right)$ using an atomizer. After sealing the plants inside plastic propagators or polythene bags lined with wet tissue paper to provide high humidity, they were incubated at either 25 or $15^{\circ} \mathrm{C}$ in a controlled environment chamber (16-h photoperiod and a PPFR of $40 \mu \mathrm{mol} \mathrm{m} \mathrm{m}^{-2} \mathrm{~s}^{-1}$.

\section{Sequencing and analysis of rDNA-ITS region.}

Fungal mycelium was produced in V8 Czapek-Dox liquid medium (Sherriff et al. 1994). Established methods were used for DNA extraction and amplification, and sequencing of rDNA-ITS regions (Sreenivasaprasad et al. 1992; Talhinhas et al. 2002). Sequence files were assembled and edited using the EditSeq and SeqMan modules of the Lasergene software package (DNAStar, Madison, WI, U.S.A.) and a consensus sequence for each isolate was compiled into a single file (Fasta 
format). Percent similarity was calculated using the MegAlign module in Lasergene. The ITS sequences for reference isolates of C. destructivum, C. higginsianum, C. acutatum, C. graminicola, $C$. gloeosporioides, and $C$. lindemuthianum were downloaded from the EMBL database (Table 1), along with that of Neurospora crassa (M13906). Sequences were aligned using CLUSTAL W (Thompson et al. 1994). Phylogenetic analyses were performed with the phylogeny inference package PHYLIP version 3.57c (University of Washington, Seattle, U.S.A.). Multiple data sets were generated by bootstrapping (SEQBOOT) and then analyzed by the DNA parsimony method (DNAPARS). A consensus tree was generated using CONSENSE and read with TreeView (Institute of Biomedical and Life Sciences, University of Glasgow, U.K.). The ITS sequences generated in this study were submitted to the EMBL database.

\section{Agrobacterium-mediated transformation.}

The binary vector pBin-GFP-hph used for the Agrobacterium-mediated transformation of $C$. destructivum is shown in Figure 6 . The plasmid was constructed by inserting the SGFPTYG coding sequence (Chiu et al. 1996) and the hygromycin B phosphotransferase ( $h p h)$ gene, each under the control of the Aspergillus nidulans glyceraldehyde-3-phosphate dehydrogenase $(g p d A)$ promoter, into the binary vector pDHt (Mullins et al. 2001). Germinating conidia of $C$. destructivum isolate IMI 349061 were transformed with Agrobacterium tumefaciens carrying the vector according to the methods of Mullins and associates (2001) and de Groot and associates (1998). Fungal DNA was isolated by the procedure of Dellaporta and associates (1983). For Southern blot analysis, $5 \mu \mathrm{g}$ of DNA was loaded per lane and hybridization conditions were as described previously (Centis et al. 1996).

\section{Light microscopy.}

To visualize fungal colonization of host tissues, samples were decolorized in ethanol-chloroform (3:1, vol/vol) and stained with $0.025 \%$ (wt/vol) Aniline blue in lactophenol. To assess the viability of infected host cells, excised hypocotyl segments (1 to $2 \mathrm{~mm}$ ) were treated with a solution of $0.85 \mathrm{M}$ $\mathrm{KNO}_{3}$ (pH 7.4) containing $0.01 \%$ (wt/vol) Neutral Red (O'Connell et al. 1993). To localize callose deposits, tissues were decolorized with ethanol-chloroform and stained with $0.01 \%$ (wt/vol) Aniline blue in $0.15 \mathrm{M} \mathrm{K}_{2} \mathrm{HPO}_{4}$ (Fernandez and Heath 1986). To detect hydrogen peroxide formation, tissues were stained with $0.1 \%$ (wt/vol) 3,3-diaminobenzidine ( $\mathrm{pH} 4.0$ ) for $12 \mathrm{~h}$ at $20^{\circ} \mathrm{C}$ (Thordal-Christensen et al. 1997), before decolorizing in ethanol-chloroform and clearing in lactophenol. For immunofluorescence labeling of fungal infection structures in planta, infected epidermal strips taken from the abaxial leaf surface were permeabilized and labeled with monoclonal antibody UB25, specific for the biotrophy-related protein $\mathrm{CIH} 1$, or with the control antibody UBIM22, as described by Perfect and associates (2000). Specimens were viewed using either differential interference contrast or epifluorescence optics.

\section{Confocal microscopy.}

To examine fungal infection structures expressing GFP, intact A. thaliana cotyledons and hypocotyl segments were mounted under a coverslip in deionized water and observed with a Leica TCS-SP confocal laser scanning microscope using a Planapo x63, 1.2 NA water immersion objective. The 488-nm line of the argon laser was used for excitation and GFP fluorescence was collected between 500 and $530 \mathrm{~nm}$ and the red autofluorescence of chlorophyll between 590 and $630 \mathrm{~nm}$.

\section{Electron microscopy.}

Excised segments of Arabidopsis thaliana hypocotyl tissue ( 2 to $3 \mathrm{~mm}$ long) were fixed in $2.5 \%$ ( $\mathrm{vol} / \mathrm{vol}$ ) glutaraldehyde in $0.05 \mathrm{M}$ sodium phosphate buffer $(\mathrm{pH} 7.5)$ for $18 \mathrm{~h}$ at $4^{\circ} \mathrm{C}$, including $5 \mathrm{~min}$ of vacuum infiltration, followed by $2 \%$ (wt/vol) osmium tetroxide in the same buffer for $2 \mathrm{~h}$ at $20^{\circ} \mathrm{C}$. After embedding in Spurr's epoxy resin, ultrathin sections were stained with uranyl acetate and lead citrate and examined by TEM (Wharton et al. 2001).

\section{ACKNOWLEDGMENTS}

R. O'Connell was supported by a CNRS research associateship, and C. Herbert and M. Khatib were supported by pre-doctoral fellowships from the Ministère de la Recherche et la Technologie (France) and SARC (Syria), respectively. Preliminary work for this study was done at IACRLong Ashton Research Station, Bristol, U.K. We thank J. Turner (University of East Anglia) and Y. Marco (INRA, Toulouse) for seed of the Arabidopsis mutants, S. Kang (Pennsylvania State University) for the binary vector $\mathrm{pDHt}$, S. Muthumeenakshi (HRI) for help with sequencing, and J. Bailey and M. Rickauer for critical reading of the manuscript.

\section{LITERATURE CITED}

Adam, L., Ellwood, S., Wilson, I., Saenz, G., Xiao, S., Oliver, R. P., Turner, J. G., and Somerville, S. 1999. Comparison of Erysiphe cichoracearum and E. cruciferarum and a survey of 360 Arabidopsis thaliana accessions for resistance to these two powdery mildew pathogens. Mol. Plant-Microbe Interact. 12:1031-1043.

Bailey, J. A., and Jeger, M. J. 1992. Colletotrichum-Biology, Pathology and Control. CAB International, Wallingford, U.K.

Bailey, J. A., Nash, C., O'Connell, R. J., and Skipp, R. A. 1990. Infection process and host specificity of a Colletotrichum species causing anthracnose disease of cowpea, Vigna unguiculata. Mycol. Res. 94:810-814.

Bennett, M., Gallagher, M., Fagg, J., Bestwick, C., Paul, T., Beale, M. and Mansfield, J. 1996. The hypersensitive reaction, membrane damage and accumulation of autofluorescent phenolics in lettuce cells challenged by Bremia lactucae. Plant J. 9:851-865.

Botella, M. A., Parker, J. E., Frost, L. N., Bittner-Eddy, P. D., Beynon, J. L., Daniels, M. J., Holub, E. B., and Jones, J. D. G. 1998. Three genes of the Arabidopsis RPP1 complex resistance locus recognize distinct Peronospora parasitica avirulence determinants. Plant Cell 10:1847-1860.

Centis, S., Guillas, I., Séjalon, N., Esquerré-Tugayé, M.-T., and Dumas, B. 1997. Endopolygalacturonase genes from Colletotrichum lindemuthianum: cloning of CLPG2 and comparison of its expression to that of CLPG1 during saprophytic and parasitic growth of the fungus. Mol. Plant-Microbe Interact. 10:769-775.

Chaure, P., Gurr, S. J., and Spanu, P. 2000. Stable transformation of Erysiphe graminis, an obligate biotrophic pathogen of barley. Nat. Biotechnol. 18:205-207.

Chen, N., Hsiang, T., and Goodwin, P. H. 2003. Use of green fluorescent protein to quantify the growth of Colletotrichum during the infection of tobacco. J. Microbiol. Methods 53:113-122.

Chiu, W. L., Niwa, Y., Zeng, W., Hirano, T., Kobayashi, H., and Sheen, J. 1996. Engineered GFP as a vital reporter in plants. Curr. Biol. 6:325-330.

de Groot, M. J. A., Bunduck, P. Hooykaas, P. J. J., and Beijersbergen, A. G. M. 1998. Agrobacterium tumefaciens-mediated transformation of filamentous fungi. Nat. Biotechnol. 16:839-842.

de Jong, C. F., Takken, F. L. W., Cai, X., de Wit, P. J. G. M., and Joosten, M. H. A. J. 2002. Attenuation of Cf-mediated defense responses at elevated temperatures correlates with a decrease in elicitor-binding sites. Mol. Plant-Microbe Interact. 15:1040-1049.

Delaney, T. P., Uknes, S., and Vernooij, B. 1994. A central role of salicylic acid in plant disease resistance. Science 266:1247-1250.

Dellaporta, S. L., Wood, J., and Hicks, J. B. 1983. A plant DNA minipreparation version II. Plant Mol. Biol. Rep. 1:19-21.

Dufresne, M., Perfect, S., Pellier, A. L., Bailey, J. A., and Langin, T. 2000. A GAL4-like protein is involved in the switch between biotrophic and necrotrophic phases of the infection process of Colletotrichum lindemuthianum on common bean. Plant Cell 12:1579-1590.

Epstein, L., Lusnak, K., and Kaur, S. 1998. Transformation-mediated developmental mutants of Glomerella graminicola (Colletotrichum graminicola). Fungal Genet. Biol. 23:189-203.

Erikson, F. L., Holzberg, S., Calderon-Urrea, A., Handley, V., Axtell, M., Corr, C., and Baker, B. 1999. The helicase domain of the TMV replicase proteins induces the $\mathrm{N}$-mediated defense response in tobacco. Plant J. 18:67-75. 
Fernandez, M. R., and Heath, M. C. 1986. Cytological responses induced by five phytopathogenic fungi in a nonhost plant, Phaseolus vulgaris. Can. J. Bot. 64:648-657.

Feys, B., Benedetti, C. E., Penfold, C. N., and Turner, J. G. 1994. Arabidopsis mutants selected for resistance to the phytotoxin coronatine are male sterile, insensitive to methyl jasmonate, and resistant to a bacterial pathogen. Plant Cell 6:751-759.

Guzmann, P., and Ecker, J. R. 1990. Exploiting the triple response of Arabidopsis to identify ethylene-related mutants. Plant Cell 2:513-523.

Herbert, C., Jacquet, C., Borel, C., Esquerré-Tugayé, M. T., and Dumas, B. 2002. A cis-acting sequence homologous to the yeast filamentation and invasion response element regulates expression of a pectinase gene from the bean pathogen Colletotrichum lindemuthianum. J. Biol. Chem. 277: 29125-29131.

Higgins, B. B. 1917. A Colletotrichum leafspot of turnips. J. Agric. Res. 10:157-161

Holub, E. B., Brose, E., Tor, M., Clay, C., Crute, I. R., and Beynon, J. L. 1995. Phenotypic and genotypic variation in the interaction between Arabidopsis thaliana and Albugo candida. Mol. Plant-Microbe Interact. 8:916-928.

Judelson, H. S. 1996. Recent advances in the genetics of Oomycete plant pathogens. Mol. Plant-Microbe Interact. 9:443-449.

Koch, E., and Slusarenko, A. J. 1990a. Arabidopsis is susceptible to infection by a downy mildew fungus. Plant Cell 2:437-445.

Koch, E., and Slusarenko, A. J. 1990b. Fungal pathogens of Arabidopsis thaliana (L.) Heyhn. Bot. Helv. 100:257-268.

Latunde-Dada, A. O., Bailey, J. A., and Lucas, J. A. 1997. Infection process of Colletotrichum destructivum O'Gara from lucerne (Medicago sativa L.). Eur. J. Plant Pathol. 103:35-41.

Latunde-Dada, A. O., O'Connell, R. J., Nash, C., Pring, R. J., Lucas, J. A., and Bailey, J. A. 1996. Infection process and identity of the hemibiotrophic anthracnose fungus (Colletotrichum destructivum O'Gara) from cowpea (Vigna unguiculata (L.) Walp.). Mycol. Res. 100:1133-1141.

Moriwaki, J., Ohkubo, H., Horie, H., Kasuyama, S., and Sato, T. 1997. Genotypic differences between Colletotrichum higginsianum and $C$. gloeosporioides based on arbitrarily primed PCR analysis. Ann. Phytopathol. Soc. Jpn. 63:395-398.

Mullins, E. D., Chen, X., Romaine, P., Raina, R., Geiser, D. M., and Kang, S. 2001. Agrobacterium-mediated transformation of Fusarium oxysporum: an efficient tool for insertional mutagenesis and gene transfer. Phytopathology 91:173-180.

Mullins, E. D., and Kang, S. 2001. Transformation: a tool for studying fungal pathogens of plants. Cell. Mol. Life Sci. 58:2043-2052.

O'Connell, R. J., Bailey, J. A., and Richmond, D. V. 1985. Cytology and physiology of infection of Phaseolus vulgaris by Colletotrichum lindemuthianum. Physiol. Plant Pathol. 27:75-98.

O’Connell, R. J., Uronu, A. B., Waksman, G., Nash, C., Keon, J. P. R., and Bailey, J. A. 1993. Hemibiotrophic infection of Pisum sativum by Colletotrichum truncatum. Plant Pathol. 42: 774-783.

Parker, J. E., Feys, B. J., Biezen, E. A. van der, Noel, L., Aarts, N., Austin, M. J., Botella, M. A., Frost, L. N. Daniels, M. J., and Jones, J. D. G. 2000. Unravelling $\mathrm{R}$ gene-mediated disease resistance pathways in Arabidopsis. Mol. Plant Pathol. 1:17-24.

Perfect, S. E., Hughes, H. B., O’Connell, R. J., and Green, J. R. 1999. Colletotrichum: a model genus for studies on pathology and fungalplant interactions. Fungal Genet. Biol. 27:186-198.

Perfect, S. E., Pixton, K. L., O’Connell, R. J., and Green, J. R. 2000. The distribution and expression of a biotrophy-related gene, $\mathrm{CIH1}$, within the genus Colletotrichum. Mol. Plant Pathol. 1:213-221.

Redman, R. S., Ranson, J. C., and Rodriguez, R. J. 1999. Conversion of the pathogenic fungus Colletotrichum magna to a nonpathogenic, endophytic mutualist by gene disruption. Mol. Plant-Microbe Interact. 12:969-975.

Redman, R. S., and Rodriguez, R. J. 1994. Factors which affect efficient transformation of Colletotrichum species. Exp. Mycol. 18:230-246.

Reuber, T. L., Plotnikova, J. M., Dewdney, J., Rogers, E. E., Wood, W. and Ausubel, F. M. 1998. Correlation of defense gene induction defects with powdery mildew susceptibility in Arabidopsis enhanced disease susceptibility mutants. Plant J. 16:473-485.

Robinson, M., and Sharon, A. 1999. Transformation of the bioherbicide
Colletotrichum gloeosporioides $\mathrm{f}$. $\mathrm{sp}$. aeschynomene by electroporation of germinated conidia. Curr. Genet. 36:98-104.

Roetschi, A., Si-Ammour, A., Belbahri, L., Mauch, F., and Mauch-Mani, B. 2001. Characterization of an Arabidopsis-Phytophthora pathosystem: Resistance requires a functional PAD2 gene and is independent of salicylic acid, ethylene and jasmonic acid signalling. Plant J. 28:293305.

Scheffer, R. P. 1950. Anthracnose leafspot of crucifers. N. C. Agric. Exp. Stn. Tech. Bull. 92

Shen, S., Goodwin, P. H., and Hsiang, T. 2001. Hemibiotrophic infection and identity of the fungus, Colletotrichum destructivum, causing anthracnose of tobacco. Mycol. Res. 105:1340-1347.

Sherriff, C., Whelan, M. J., Arnold, G. M., Lafay, J.-R., Brygoo, Y., and Bailey, J. 1994. Ribosomal DNA sequence analysis reveals new species groupings in the genus Colletotrichum. Exp. Mycol. 18:121-138.

Sreenivasaprasad, S., Brown, A. E., and Mills, P. R. 1992. DNA sequence and interrelationships among Colletotrichum species causing strawberry anthracnose. Physiol. Mol. Plant Pathol. 41:265-281.

Sreenivasaprasad, S., Mills, P. R., Meehan, B., and Brown, A. E. 1996. Phylogeny and systematics of 18 Colletotrichum species based on ribosomal DNA sequences. Genome 39:499-512.

Sutton, B. C. 1980. The Coelomycetes: Fungi Imperfecti with Pycnidia Acervuli and Stromata. Commonwealth Mycological Institute, Kew, U.K.

Sutton, B. C. 1992. The genus Glomerella and its anamorph Colletotrichum. Pages 1-26 in: Colletotrichum-Biology, Pathology and Control. J. A Bailey, and M. J. Jeger, eds. CAB International, Wallingford, U.K.

Takano, Y., Kubo, Y., Kuroda, I., and Furusawa, I. 1997. The temporal transcriptional pattern of three melanin biosynthesis genes $P K S 1, S C D 1$ and THRI in appressorium-differentiating and nondifferentiating conidia of Colletotrichum. Appl. Environ. Microbiol. 63:351-354.

Talhinhas, P., Sreenivasaprasad, S., Neves-Martins, J., and Oliveira, H. 2002. Genetic and morphological characterization of Colletotrichum acutatum causing anthracnose of lupins. Phytopathology 92:986-996.

Thomma, B. P. H. J., Nelissen, I., Eggermont, K., and Broekaert, W. F. 1999. Deficiency in phytoalexin production causes enhanced susceptibility of Arabidopsis thaliana to the fungus Alternaria brassicola. Plant J. 19:163-171.

Thomma, B. P. H. J., Penninckx, I. A. M. A., Broekaert, W. F., and Cammue, B. P. A. 2001a. The complexity of disease signaling in Arabidopsis. Curr. Opin. Immunol. 13:63-68.

Thomma, B. P. H. J., Tierens, K. F. M., Penninckx, I. A. M. A., MauchMani, B., Broekaert, W. F., and Cammue, B. P. A. 2001b. Different micro-organisms differentially induce Arabidopsis disease response pathways. Plant Physiol. Biochem. 39:673-680.

Thompson, J. D., Higgins, D. G., and Gibson, T. J. 1994. CLUSTAL W improving the sensitivity of progressive multiple sequence alignment through sequence weighting, positions-specific gap penalties and weight matrix choice. Nucleic Acids Res. 22:4673-4680.

Thon, M. R., Nuckles, E. M., and Vaillancourt, L. J. 2000. Restriction enzyme-mediated integration used to produce pathogenicity mutants of Colletotrichum graminicola. Mol. Plant-Microbe Interact. 13:13561365.

Thordal-Christensen, H., Zhang, Z., Wei, Y., and Collinge D. B. 1997. Subcellular localization of $\mathrm{H}_{2} \mathrm{O}_{2}$ in plants. $\mathrm{H}_{2} \mathrm{O}_{2}$ accumulation in papillae and hypersensitive response during the barley-powdery mildew interaction. Plant J. 11:1187-1194.

von Arx, J. A. 1957. Die Arten der Gattung Colletotrichum Cda. Phytopathol. Z. 29:413-468.

Wharton, P. S., Julian, A. M., and O'Connell, R. J. 2001. Ultrastructure of the infection of Sorghum bicolor by Colletotrichum sublineolum. Phytopathology 91:149-158.

Xiao, S. Y., Ellwood, S., Calis, O., Patrick, E., Li, T. X., Coleman, M., and Turner J. G. 2001. Broad-spectrum mildew resistance in Arabidopsis thaliana mediated by RPW8. Science 291:118-120.

Yang, Z., and Dickman, M. B. 1999. Colletotrichum trifolii mutants disrupted in the catalytic subunit of cAMP-dependent protein kinase are nonpathogenic. Mol. Plant-Microbe Interact. 12:430-439.

Zwiers, L.-H., and De Waard, M. A. 2001. Efficient Agrobacterium tumefaciens-mediated gene disruption in the phytopathogen Mycosphaerella graminicola. Curr. Genet. 39:388-393. 